\title{
LOW-COST BATTERY MONITORING SYSTEM FOR ELECTRIC VEHICLES USING SIMULINK
}

\author{
Mr. Sunil Somani \\ Assistant Professor, Dept. of ENTC, MIT College of Engineering, Kothrud, Pune \\ Prasad Dedhe, Shrey Jain, Tanishq Jadhav \\ Undergraduate Student Dept. of ENTC, MIT College of Engineering, Kothrud, Pune
}

\begin{abstract}
A battery monitoring system (BMS) is needed for proper functioning of electric vehicles $(\mathrm{EV})$. It controls the charging and discharging of battery cells. It monitors the capacity, energy level, temperature, output voltage, output current, SOH (state of health) and SOC (state of charge) of each individual cell in the battery and keeps the battery parameters under safe operating conditions. This outcome ensures the safety of the driver as well as the estimation of the available range of the $\mathrm{EV}$.
\end{abstract}

Keywords- (Battery Monitoring System (BMS), State of Charge, Overvoltage, Cell Balancing)

\section{INTRODUCTION}

Our project focuses on the challenge of fusing multiple sensor inputs to create a balanced vehicle control, which will serve to aid a driver. The primary challenge is to develop a system which accurately measures the different battery parameters and provides the information and analysis in real time.

The master microcontroller will be programmed and instructed with MATLAB coding language. The software used is CCS (Code Composer Studio). The slave microcontrollers are controlled by master but are programmed in Embedded $\mathrm{C}$ language. The software used is Arduino IDE.

The TI C2000 microcontroller works to control all sensors. It receives the signals from the sensors and this signal is operated under the control of software which is stored in ROM. Microcontroller TI C2000 continuously monitors the data, and if the system is behaving abnormally, it corrects that behavior. In case of mechanical faults, it informs the driver.

The aim of this project is to help the driver of an electric vehicle to overcome the fear of sudden battery failure due to lack of power, overheating, etc.

\section{LiteratURE SURVEY}

The important factor to consider is real- time calculation and analysis of the data, which is performed by the combination of Hardware and Software. In recent years, a control unit mounting a single-chip micro-computer is used in vehicle control. The single-chip micro-computer incorporates memories (ROM, RAM and so on) required by calculation of the central processing unit (CPU). Therefore, there is an advantage in that the control unit can be miniaturized as a whole, being easy in use and high in processing speed. As computing power increases, we are capable to add a lot of inferior features.

As a result, it is imperative for us to opt for the perfect fit as per requirement of the system. Therefore, a wide research about components, their electrical alignment is required. Also, it is axiomatic, that the cost of overall design must be within constraint. In software section, it is essential to develop an acute algorithm for the system to give expected result. For this purpose, an extensive survey was conducted by Texas instruments.

During the charging and discharging of an EV battery, it is imperative that each cell within the battery pack is closely and accurately monitored because any number of out-of-spec conditions can, at a minimum, quickly cause internal damage of the battery and vehicle or threaten the safety of the vehicle's occupants. A battery monitoring integrated circuit (BMIC) or cell-balancer device is typically assigned to monitor the voltage of each battery cell in a module, the temperature of various points in the module and other conditions. This data is reported to a cell management controller (CMC) and, depending on the complexity of the system, on to higher-order processing elements, such as one or more battery management controllers (BMC). The precision of these measurements and the frequency of the communications from the BMIC to the CMC and BMC is key to detecting a condition of concern early on and taking corrective action before it becomes hazardous.

TI's Hercules ${ }^{\mathrm{TM}}$ TMS570 MCUs are certified by TÜV SÜD as meeting ISO 26262:2011 requirements up to ASIL-D. TÜV SÜD is an internationally recognized and independent assessor of compliance with quality and safety standards. The Hercules MCU family is a scalable family with the functional and safety architectures the same from MCU to MCU. There are pin-to-pin compatible MCUs from $128 \mathrm{~KB}$ Flash to $4 \mathrm{MB}$ and $80 \mathrm{MHz}$ to $300 \mathrm{MHz}$ TI Hercules TMS570 MCUs offer dual-core CPU lockstep/compare and memory Error Correction Code (ECC) real-time diagnostics, as well as hardware-based CPU Logic Built-In Self-Test (LBIST) and SRAM Programmable Built-In Self-Test (PBIST). These hardware-based safety features help diagnose errors in mission-critical blocks and offer high diagnostic coverage with minimum software overhead.

The Hercules series of MCU's meet all the requirements of the battery management controller to be use 
in our project and hence are chosen as the primary MCU in our system architecture.

\section{IMPLEMENTATION}

\section{A. Block Schematic}

In this model we are using TI Hercules TMS570LS04 32bit RISC flash microcontroller. The safety architecture includes dual CPUs in lockstep, CPU and Memory BIST logic, ECC on both the flash and the data SRAM, parity on peripheral memories, and loopback capability on peripheral I/O. Battery monitoring and protection block keeps the battery parameters in safe operating conditions and send that data to Arduino. The data from current and temperature sensors is also sent to Arduino. This data is further sent to TMS5704 which is the main control unit. GPS and RFID modules are used for speed control of the DC motor. Any fault in motor and other mechanical components is detected and alert is indicated using warning LED and buzzer.

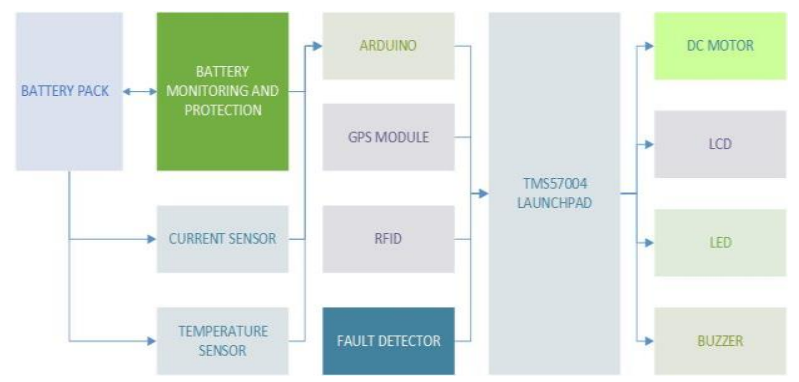

Fig. 1: Block Schematic

\section{B. Algorithm}

Step 1: System will start up as it gets the key from the user.

Step 2: On board circuitry in the system tells the MPU voltage of each cell and it is read by the microcontroller.

Step 3: If there the condition of battery is unwanted then it alerts the MPU and it starts to control it using onboard circuitry.

Step 4: MPU then again monitors condition of battery and if it is unsafe it immediately alerts the driver.

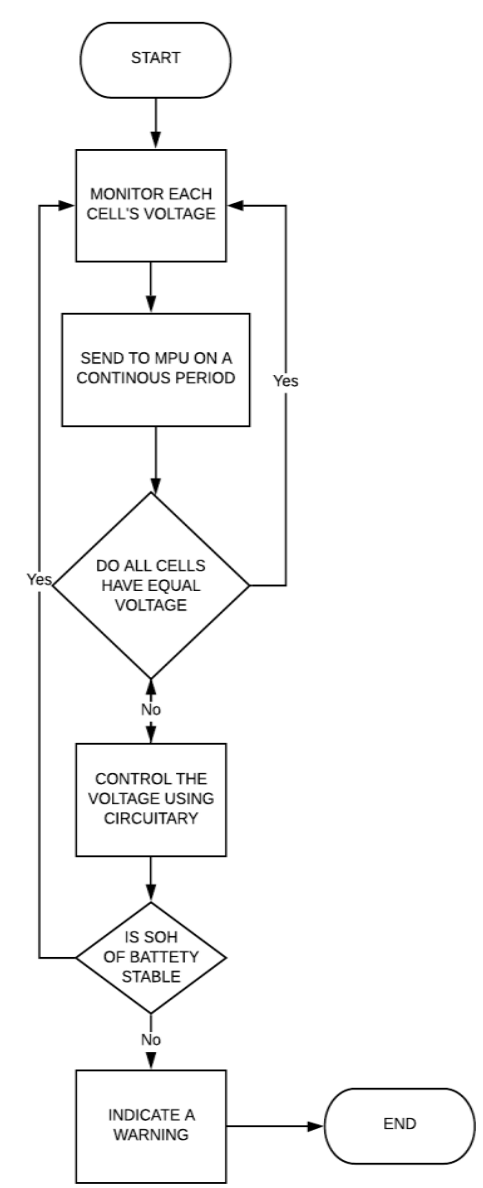

Fig. 2: Flowchart of BMS

\section{Simulink Simulation}

The following screenshots show our implementation of the BMS model on Simulink.

The main model consists of two parts: 1) Battery Software and 2) Battery Model

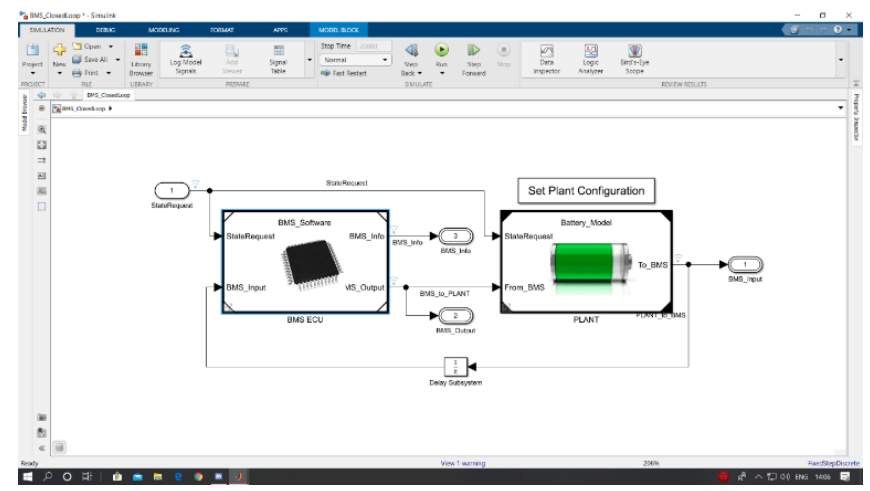

Fig. 3: BMS System

1) Battery Software 
The battery software has a main state machine which contains all the necessary algorithms and logic for the proper functioning of the BMS System. Along with this, it contains the Cell Balancing and SOC Estimation state machines which control these two functions.

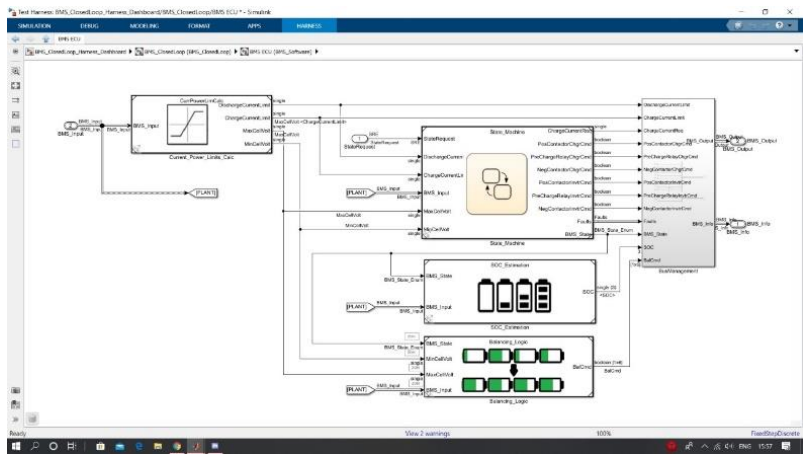

Fig. 4: BMS Software System

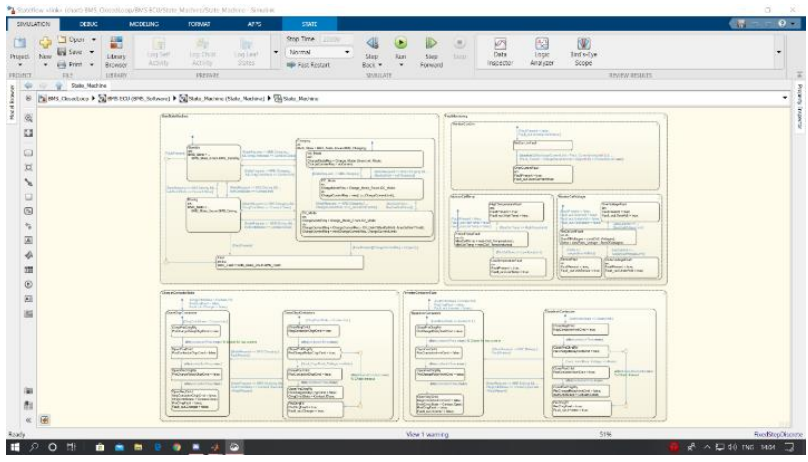

Fig. 5: Main State Machine

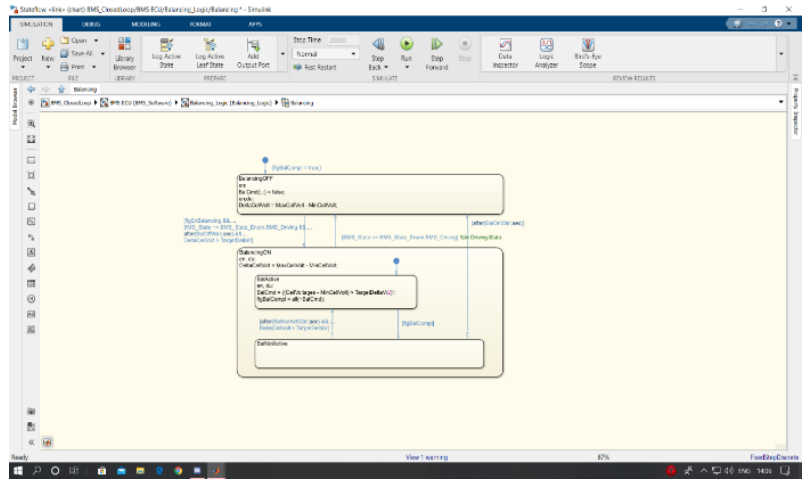

Fig. 6: Cell Balancing State Machine

\section{2) Battery Model}

The battery model consists of the pre-charge circuit and a battery pack of 16 modules. These 16 modules further consist of 6 cells each.

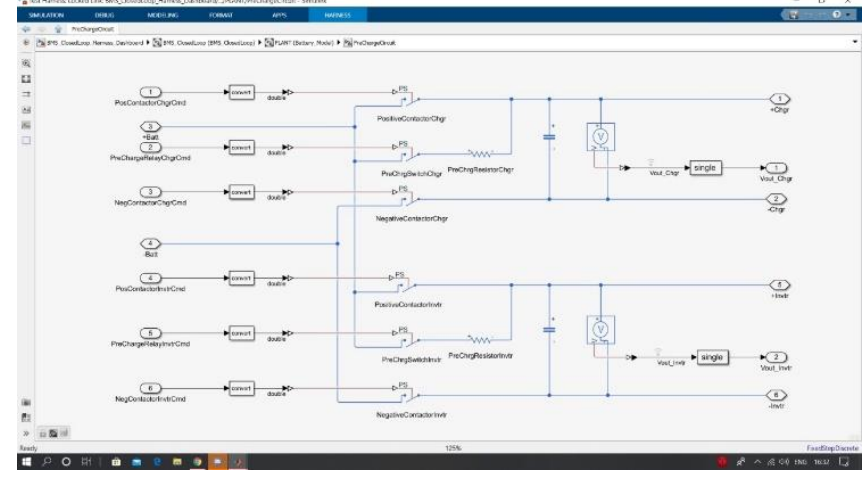

Fig. 7: Pre-charge Circuit

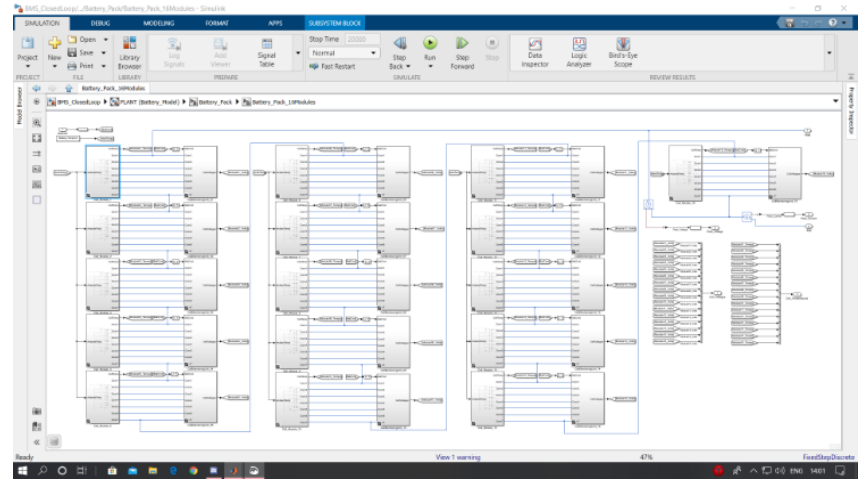

Fig. 8.: Battery Pack with 16 modules

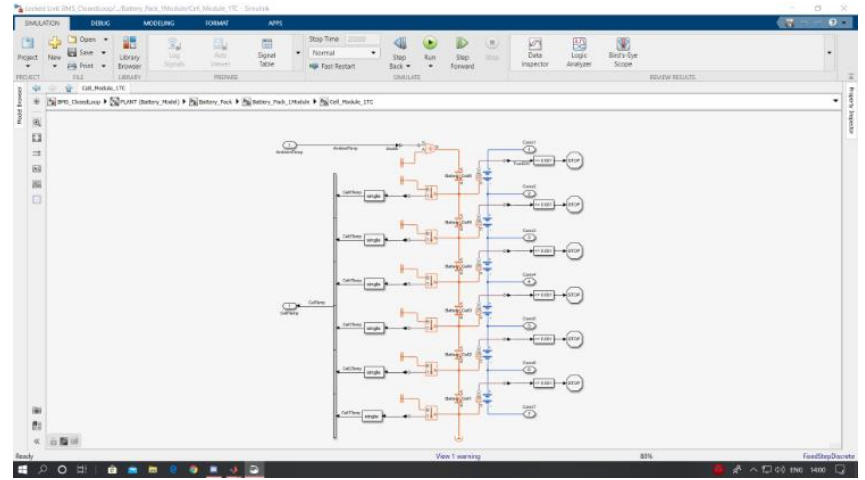

Fig. 9: 1 Module with 6 cells

Hence the battery model, along with the battery software and the FSM logic encompasses the system architecture on Simulink. The BMS software controls an IC circuit based on the TMS320 MCU. This circuit directly interfaces with the battery (battery model in case of the simulation) and controls and implements all the essential functions such as SOC Estimation, Cell Balancing, and monitoring of battery parameters which exceed the safe operating conditions.

\section{RESUlTS}

After building our BMS model on Simulink, the entire simulation was run for 2 different test cases:

(1) In test case-1, the driving conditions of an EV were simulated first. After a set amount of time, the driving 
state was stopped and the model was put into the charging state, which simulated the normal charging of the EV. It was observed that during the driving conditions, the SOC, voltage and current steadily decreased. While, the cell temperature increased slowly during the driving conditions, it increased rapidly for the charging duration. This signifies the heat generation which is usually observed when lithium-ion batteries are charged.

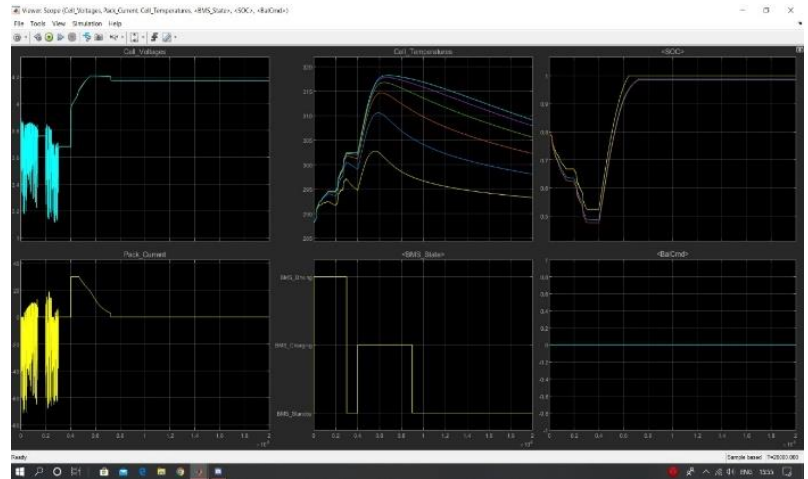

Fig. 10: Test case - 1

(2) In test case-2, the simulation was again started in the driving condition. But this time the driving state lasted until the entire battery was depleted and the state of charge (SOC) reached to 0. Again, it was observed that the temperature increased slowly during this state. However, in test case 2, it was additionally observed that when the SOC reached 0 , the cell voltages in different cells of the battery were at different values. This state of the cells signified an unbalanced state, which occurs when the battery is under prolonged use. To overcome this state, a balancing circuit is also present in our simulation model. When the SOC became 0, this balancing circuit was activated. Soon after this activation, all the different cell voltages reached to the same value of roughly $3.52 \mathrm{~V}$, signifying the balanced state of the battery.

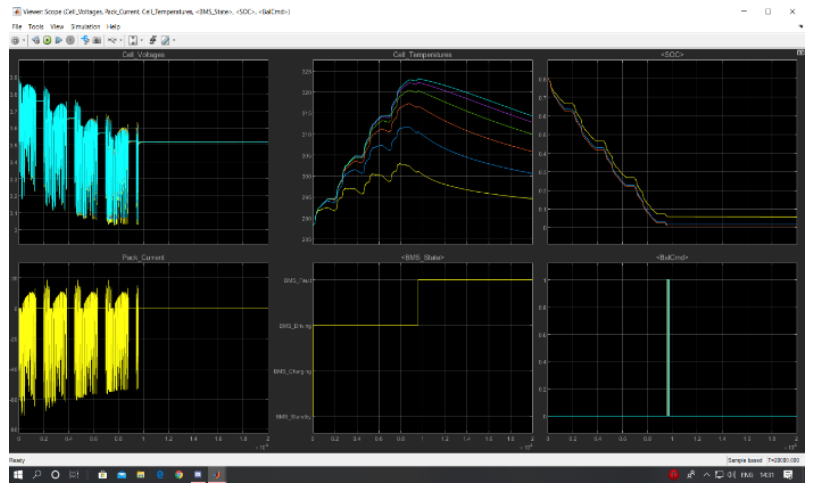

Fig. 11: BMS Charging Cells

Additionally, on our simulation dashboard there are multiple fault switches present which get switched on whenever a fault is detected. This aids the user/driver in monitoring the BMS system easily.

In the screenshot below you can see that during our simulation test cases, the "HighTemp" fault state was activated during the second test case when the model was under full driving condition.

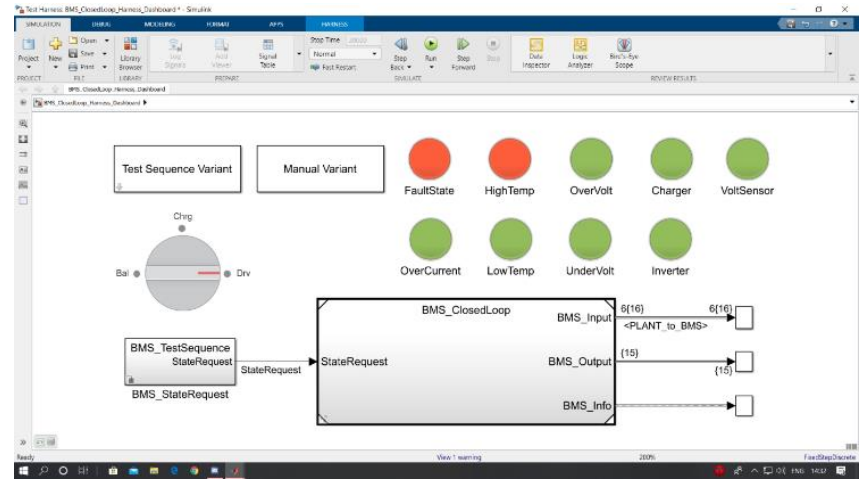

Fig. 12: BMS fault detection

Hence the simulation shows that our implementation of a battery model is accurate and its performance is similar to real-world scenarios.

The discussion of the performance of the BMS is done in the next section.

\section{CONCLUSION}

It was observed that the primary objective of our project i.e. building a fully functional Battery Monitoring System, was fulfilled. In our simulation runs, the driving, charging, and balancing states were functioning as expected and the results were satisfactory. Using our model, the monitoring of Electric Vehicles battery packs becomes very ergonomic for the user. Any risky conditions/faults in the model are also indicated on the dashboard whenever they occur, resulting in increased safety for the user.

All the components used by our team can be easily procured from the market and are cheap, ensuring the lowcost feature of our setup which is necessary for growth markets of electric vehicles.

\section{ACKNOWLEDGMENT}

The following work was done as a part of our final year under-graduate project, under the guidance of our project guide Prof. S.B. Somani.

\section{REFERENCES}

[1] Kumar B., Khare N. and Chaturvedi P. K., (2015), "Advanced battery management system using MATLAB/Simulink," 2015 IEEE International Telecommunications Energy Conference (INTELEC), Osaka, 2015, pp. 1-6, doi: 10.1109/INTLEC.2015.7572447.

[2] Xu D., Wang L. and Yang J., (2010), "Research on Liion Battery Management System," 2010 International 


\section{International Journal of Engineering Applied Sciences and Technology, 2020 Vol. 5, Issue 3, ISSN No. 2455-2143, Pages 277-279 \\ Published Online July 2020 in IJEAST (http://www.ijeast.com)}

Conference on Electrical and Control Engineering, Wuhan, 2010, pp. 4106-4109, doi: 10.1109/iCECE.2010.998.

[3] M, Brandl \& H, Gall \& M, Wenger \& Lorentz, Vincent \& Giegerich, Martin \& Baronti, Federico \& G, Fantechi \& Fanucci, Luca \& Roncella, Roberto \& Saletti, Roberto \& Saponara, Sergio \& A, Thaler \& Cifrain, Martin \& W, Prochazka. (2012). Batteries and battery management systems for electric vehicles. 971-976. 10.1109/DATE.2012.6176637.

[4] Chon Sang and Beall Jon, (2017), Intelligent battery management and charging for electric vehicles (C) 2017 Texas Instruments Incorporated - SPRY304A

[5] Gerding, E.; Robu, V.; Stein, S.; Parkes, D.; Rogers, A.; and Jennings, N. 2011. Online mechanism design for electric vehicle charging. In The Tenth International Joint Conference on Autonomous Agents and MultiAgent Systems (AAMAS 2011), 811-818.

[6] Yuksel, T.; Michalek, J.J. 2015. Effects of Regional Temperature on Electric Vehicle Efficiency, Range, and Emissions in the United States. Environ. Sci. Technol, 49, 3974-3980.

[7] de Cauwer, C.; Maarten, M.; Coosemans, T.; van Mierlo, J.; Heyvaert, S. 2015. Electric vehicle use and energy consumption based on real-world electric vehicle fleet trip and charge data and its impact on existing EV research models. In Proceedings of the International Electric Vehicle Symposium and Exhibition, Kintex, Korea; pp. 1-11.

[8] Emadi, A.; Rajashekara, K.; Williamson, S.S.; Lukic, S.M. 2005. Topological overview of hybrid electric and fuel cell vehicular power system architectures and configurations. IEEE Trans. Veh. Technol. 54, 763-770.

[9] Cooper, A.; Furakawa, J.; Lam, L.; Kellaway, M. 2009. The ultrabattery-A new battery design for a new beginning in hybrid electric vehicle energy storage. J. Power Sources, 188, 642-649.

[10] Van Mierlo, J.; Maggetto, G.; van den Bossche, P. 2004. Models of energy sources for EV and HEV: Fuel cells, batteries, ultra-capacitors, flywheels and enginegenerators. J. Power Sources, 28, 76-89.

[11] Burke, A.F. 2007. Batteries and ultracapacitors for electric, hybrid, and fuel cell vehicles. Proc. IEEE, 95, 806-820.

[12] Onda, K.; Ohshima, T.; Nakayama, M.; Fukuda, K.; Araki, T. 2006. Thermal behaviour of small lithium-ion battery during rapid charge and discharge cycles. J. Power Sources, 158, 535-542.

[13] Lee, S.; Kim, J.; Lee, J.; Cho, B.H. 2008. State-of-charge and capacity estimation of lithium-ion battery using a new open-circuit voltage versus state-of-charge. J. Power Sources, 185, 1367-1373.

[14] Dubary, M.; Svoboda, V.; Hwu, R.; Law, B.Y. 2007. A roadmap to understand battery performance in electric and hybrid vehicle operation. J. Power Sources, 174, 366-372.

[15] MATLAB Simulink Tutorials: https://www.mathworks.com/solutions/powerelectronics-control/battery-management-system.html 